\title{
RESISTANCE OF POLYLACTIDE MATERIALS TO WATER MEDIUMS OF THE VARIOUS NATURES
}

\author{
Volodymyr Levytskyi ${ }^{1,2}$, Diana Katruk ${ }^{1}$, Andriy Masyuk ${ }^{1, 凶}$ \\ Khrystyna Kysil ${ }^{1}$, Mykhailo Bratychak Jr. ${ }^{1}$, Nataliia Chopyk ${ }^{1}$
}

https://doi.org/10.23939/chcht15.02.191

\begin{abstract}
The influence of talc filler, its content, as well as an additional heat treatment and temperature on the regularities of polylactide materials water-absorption has been researched. Based on the obtained data, the water diffusion coefficient in polylactide materials and the activation energy of the diffusion process were determined. It was found that the process of water absorption by the filled and heat-treated materials based on polylactide proceeds slower and requires more activation energy of the process. Stability of the developed polylactide materials to acidic and alkaline media has been determined, in particular, it was found that the destruction of polylactide samples occurs faster in an alkaline medium than in an acidic one.
\end{abstract}

Keywords: polylactide, water absorption, chemical resistance, talc, heat treatment.

\section{Introduction}

Nowadays, there is a considerable interest in the polymer materials application of high biodegradability which would be synthesized on the basis of reproducible natural resources $[1,2]$. First of all, it is related to the pollution of the environment with waste polymer materials and products based on them, as well as the exhaustion and regular increase in prices for the natural resources including oil, coal, natural gas, which are widely used for synthetic polymers production. In this regard, along with other biodegradable polymer materials a special attention is focused on the polylactides and materials which are based on them [3-5].

Polylactide (PLA) is a product of lactic acid polycondensation which is a linear aliphatic biodegradable polyester obtained from reducing raw materials (starch).

\footnotetext{
${ }^{1}$ Lviv Polytechnic National University

12, Bandera str., 79013Lviv, Ukraine

${ }^{2}$ The John Paul II Catholic University of Lublin, 14, Al. Racławickie, 20-950 Lublin, Poland

masyukas@gmail.com

(C) Levytskyi V., Katruk D., Masyuk A., Kysil K., Bratychak Jr. M., Chopyk N., 2021
}

The melting temperature of PLA is within the range of 443-453 K which allows to process this polymer by wellknown industrial methods: injection molding, extrusion, 3D printing, etc. [6].

One of the most important issues concerning the PLA application and materials based on it is the control of in vitro and in vivo degradation that occurs in the presence of water [7]. Hydrolytic degradation of the mentioned materials usually occurs in the following stages: Diffusion of water into the material. - Hydrolysis of macromolecules chains in the amorphous area through the lower water resistance. - Decrease in the molecular weight due to hydrolytic splitting of ester bonds and the formation of water-soluble compounds. - Hydrolysis of lamella in the crystalline phase which can occur through an autocatalytic mechanism via acid degradation products, as well as increasing the concentration of carboxylic acid at the ends of the chains.

The hydrolytic degradation of polylactide is influenced by such physical and chemical factors as temperature, $\mathrm{pH}$, molecular weight of the polymer, crystallinity degree, fillers content and so on $[8,9]$.

In this regard, there is a need to study the characteristics of water absorption of polylactide and materials based on it depending on environmental conditions, to predict both the areas of application of such materials and methods of their further utilization.

At the same time, among the methods of directed influence on morphology and properties of polylactides there are their blending with fine dispersed fillers [10] and additional heat treatment [11]. So, it would be expedient to study the influence of the mentioned factors on the regularities of polylactide water-absorption and its chemical resistance to alkaline and acidic mediums.

\section{Experimental}

In the presented work for the obtaining of polylactide composites the polylactide of Ingeo $2500 \mathrm{HP}$ brand (manufactured by NatureWorks LLC) has been applied. Algol Chemicals Finntalc M05 natural talc 
mineral with a density of $2.7-2.85 \mathrm{~g} / \mathrm{cm}^{3}$ was applied as a fine dispersed filler.

The components were pre-mixed in the desired ratio using a drum type mixer (powdering a granular thermoplastic with talc) for 15-20 min. After obtaining the mechanical blend, it was dried for $1.5-2 \mathrm{~h}$ in an air vacuum dryer of 2B-131 type at $343 \mathrm{~K}$. Further homogenization of the blend was conducted via mixing in a viscous state of components on a Cellier extruder, which is equipped with a screw having a length of $700 \mathrm{~mm}$ and diameter of $25 \mathrm{~mm}$. The rotation velocity of the extruder screw is $10-15 \mathrm{rpm}$. The temperatures of the extruder zones are 438-443, 448-453 and 458-463 K. The obtained extrudate was crushed on a gear type crusher. The production of standard samples of granular material for research was conducted by the injection molding on a Krauss Maffei KM 110-520 C2 molding machine. The filler content was $0-7 \mathrm{wt} \%$. Additional heat treatment of the obtained materials was conducted in a thermal furnace at $393 \mathrm{~K}$ for $10 \mathrm{~min}$.

Water absorption of polylactide composites was determined according to ISO 62:2008. The change in a mass was recorded by the periodic removal of samples from water and by weighing on scales with the preciseness to $1 \mathrm{mg}$. The change in the mass $\left(W_{t}\right)$ as a percentage at any time moment $t$, due to water absorption was determined by Eq. (1):

$$
W_{t}=\frac{M_{d}-M_{w}}{M_{d}} \cdot 100 \%
$$

where $M_{d}$ and $M_{w}$ are the mass of the dry sample (initial) and the mass of the sample after staying in the water, respectively, $\mathrm{g}$.

The values of maximum water absorption $\left(W_{m}\right)$ were calculated as the average value of several consecutive measurements which did not show appreciable changes in the water absorption values. The mass increase which is caused by the water absorption can be expressed in two parameters: the diffusion coefficient $D$ and the maximum water absorption $W_{m}$ using Eq. (2):

$$
\frac{W_{t}}{W_{m}}=1-\frac{8}{\pi^{2}} \exp \left[-\left(\frac{D t}{h^{2}}\right) \pi^{2}\right]
$$

where $h$ is the thickness of the samples, $\mathrm{m}$.

The value of the diffusion coefficient $D$ was calculated according to Eq. (3):

$$
D=\frac{\pi h^{2}\left(W_{2}-W_{1}\right)^{2}}{16 M_{m}^{2}\left(t_{2}^{1 / 2}-t_{1}^{1 / 2}\right)^{2}}
$$

where $\frac{\left(W_{2}-W_{1}\right)^{2}}{\left(t_{2}^{1 / 2}-t_{1}^{1 / 2}\right)^{2}}$ is the sine of $\alpha$ angle in the graph of the dependence $M_{t}$ on $t^{1 / 2}$.

The diffusion activation energies $\left(E_{a}\right)$ of water for the PL composites were determined through the Arrhenius equation (4) making the dependency graph of $\ln D$ on $1 / T$ :

$$
\ln D=-\frac{E_{a}}{R T}+\ln D_{0}
$$

where $D$ is the diffusion coefficient of the sample; $D_{0}$ is an initial diffusion coefficient; $E_{a}$ is an activation energy of the water diffusion; $R$ is the gas constant $(8.314 \mathrm{~J} / \mathrm{K} \cdot \mathrm{mol})$ and $T$ is the temperature.

The chemical resistance of polylactide materials to the action of $5 \% \mathrm{H}_{2} \mathrm{SO}_{4}$ solution and $0.5-5 \% \mathrm{NaOH}$ solution was estimated according to ISO 2812-1: 2007.

The SPECORD 70 spectrograph was applied for FTIR spectroscopy; the spectra were recorded within the range of $400-4000 \mathrm{~cm}^{-1}$. Samples were prepared by pressing the tablets with $\mathrm{KBr}$.

\section{Results and Discussion}

Interest to the problem of interaction of water with polymers, as well as the polymer materials, especially which are biodegradable ones, is conditioned by the number of factors. One of them is the practical importance of information concerning the interaction of water and the polymers. At the same time, polylactide materials, due to their ability to biodegrade are beginning to be widely applied as packaging materials, disposable and so on. In this case, water and moist air are the environment which most often polymer materials and the products based on them contact with. The same conditions are usually in landfills, where the polymeric products are stored after utilization. Therefore, the data concerning the sorption properties of material [12] and water diffusion [13] are needed to predict the behavior of mentioned materials in the humid mediums as well as to assess their working ability and the water impact on polymer degradation.

At the same time, to provide polylactide materials with necessary operational and technological properties they are being modified with the fillers of different nature and the directed change in their morphology, in particular via additional heat treatment which promotes a significant increase in the crystallinity degree of the polymer [14]. For the determination of the impact of filler (talc) content and heat treatment conditions, the studies concerning water absorption of obtained polylactide materials were conducted. The kinetic dependencies of polylactide water absorption on the talc content and the heat treatment are shown in Fig. 1.

The water absorption of polylactide materials occurs by stages. At the first stage when keeping in water up to $10 \mathrm{~h}$, the rate of water absorption is quite high where upon we can observe a slowdown in water absorption and equilibrium values reaching. It should be noted that adding of talc into polylactide slightly accelerates the water absorption at the initial stage. The above mentioned obviously occurs due to the flabby polymer structure and 
the formation of transitional adsorption layers around the filler particles. Probably, at the initial stage, the swelling degree of hydrophobic polymers is as higher as more additives are in their composition. At the same time, an additional heat treatment of polylactide materials leads to a decrease in both the water absorption rate and the equilibrium value of water absorption. Such regularities of the heat treatment influence are associated with a significant compaction of the PLA materials structure owing to the increase of the crystallinity degree of the polymer. It should be noted that the increase in water temperature promotes faster establishment of equilibrium water absorption.

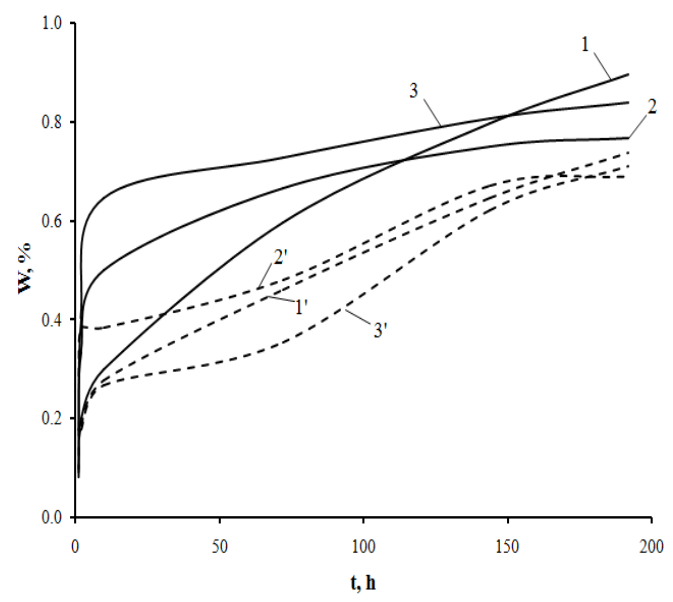

a)
Hereby there is a minor increase in water absorption values during long-term staying of polylactide in the water due to the plasticizing effect of the water leading to increased flexibility and easier orientation of PLA macromolecules [15]. At the same time, for almost all hydrophobic polymers, during their prolonged contact with water on the kinetic curves of water absorption there is a maximum associated with the process of washing up the polymer (desorption in the liquid phase).

To define the possible changes in the polylactide supramolecular structure under the heat treatment, as well as to determine the nature of intermolecular interactions between the functional groups of the hydrophobic polymer, the IR spectroscopic studies were conducted (Fig. 2).

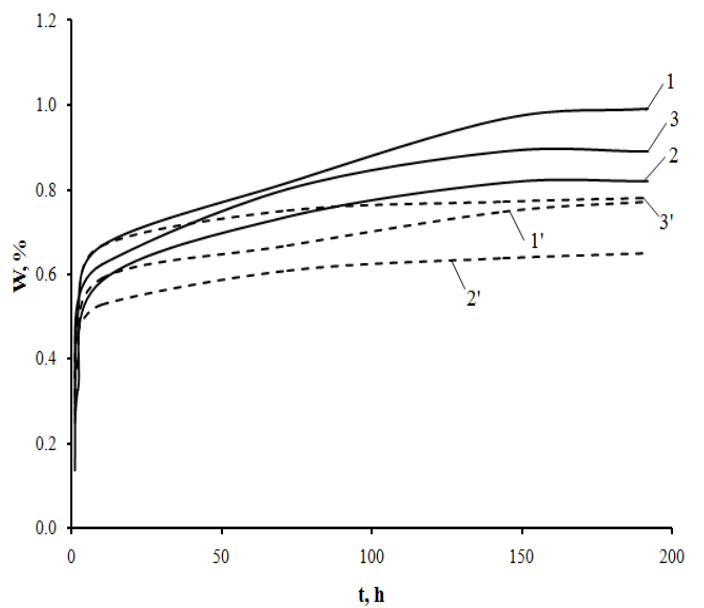

b)

Fig. 1. Dependence of water absorption of polylactide materials on time at water temperature of $276 \mathrm{~K}$ (a) and $333 \mathrm{~K}$ (b). Talc content: $0 \mathrm{wt} \%\left(1,1^{\prime}\right) ; 2 \mathrm{wt} \%\left(2,2^{\prime}\right) ; 7$ wt \% (3, 3'). 1, 2, 3 - not heat-treated samples, 1', 2', 3' - heat-treated samples

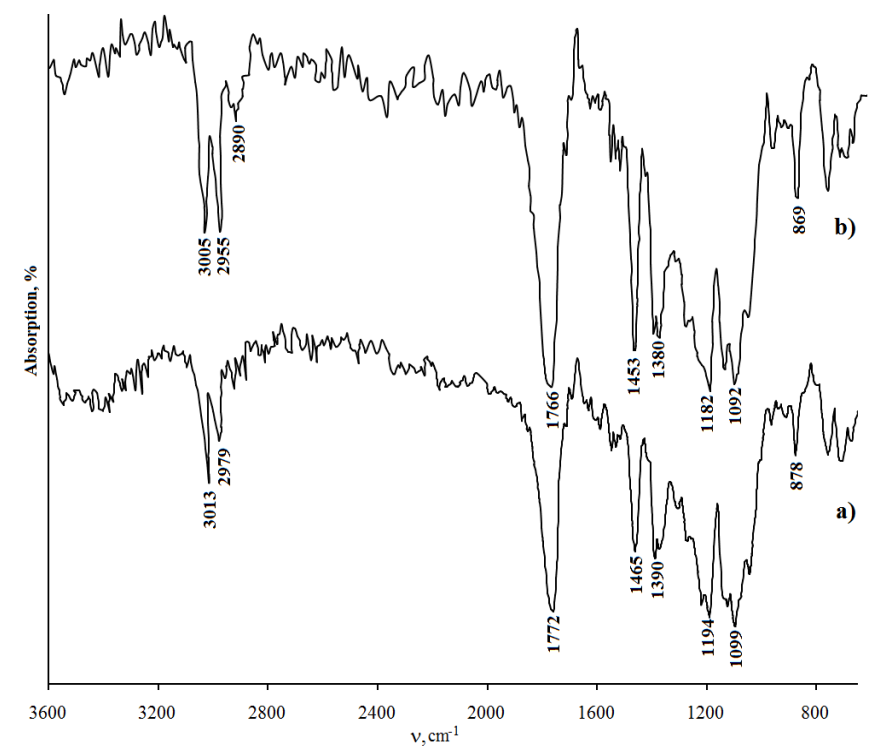

Fig. 2. IR absorption spectra of initial (a) and heat-treated polylactide (b) 
For polylactide, independently of its thermal prehistory and crystallinity degree, the absorption bands within the area of $1050-1200 \mathrm{~cm}^{-1}$ with the highest intensity due to the valence symmetric and antisymmetric oscillations of $-\mathrm{C}-\mathrm{O}-\mathrm{C}-$ ester group are typical. For all the samples, absorption bands corresponding to the valence symmetric and antisymmetric oscillations of the $\mathrm{CH}$ bond of the methylene group within the area of 2900 $3100 \mathrm{~cm}^{-1}$ are definite as well as the deformation symmetric and antisymmetric oscillations of methylene group in the range of $1380-1400$ and $1450-1470 \mathrm{~cm}^{-1}$ were also noted. The intensive absorption band observed in the range of $1760-1780 \mathrm{~cm}^{-1}$ can concern to the valence vibrations of $\mathrm{C}=\mathrm{O}$ carbonyl group in polylactide [16].

It should be emphasized that for the heat-treated polylactide a change in the intensity of characteristic bands and their insignificant shift are observed if compared to the original polylactide. The presence of a crystalline structure in the heat-treated sample being confirmed by both higher absorption intensities and the appearance of an additional absorption band within the range of $920 \mathrm{~cm}^{-1}$ which corresponds to the bending oscillations of $\mathrm{CH}$ bonds and, in our opinion, indicates intermolecular interactions in the system as well as crystallization of polylactide under the heat treatment impact. Mentioned interactions are obviously accompanied by the formation of macrochains in supramolecular structures [17].

Since the peaks of the absorption bands of the deformation oscillations for the $\mathrm{C}=\mathrm{O}$ group and the deformation symmetric and antisymmetric oscillations for the $\mathrm{CH}$ bond are shifted toward the lower values of the wave number for the initial PLA, it can be assumed that weak $\mathrm{C}-\mathrm{H} \ldots \mathrm{O}=\mathrm{C}$ hydrogen bonds are formed in the amorphous PLA.

The influence of water temperature, talc concentration and additional heat treatment on the value of equilibrium water absorption was studied (Table 1).

Based on the research conducted, it is determined that the maximum water absorption of polylactide materials is insignificant and belongs to diapason of 0.6$1.0 \mathrm{wt} \%$. Besides, the water absorption by polylactide samples was higher during the first periods of the research and gradually decreased until the saturation of the material, which testifies to the classical phenomenon of Fikkian diffusion.

In addition, the water temperature affects the water absorption of polylactide materials. The rate of diffusion of water through the material increases with increasing temperature because the mobility of polylactide macromolecules increases, that, in turn causes an increase in the probability of formation of intermolecular "cavities" through which the water molecules can diffuse. Owing to the increase in number and size of intermolecular "cavities", the rise of maximum water absorption of polylactide materials is observed.

Based on the data obtained, the diffusion coefficients of water in the polylactide materials were determined depending on the temperature, talc content and additional heat treatment (Table 2).

Table 1

Equilibrium water absorption of PLA-based composites at different temperatures

\begin{tabular}{|c|c|c|c|c|}
\hline \multirow{2}{*}{$\begin{array}{c}\text { Talc } \\
\text { content } \\
\text { wt } \%\end{array}$} & $276 \mathrm{~K}$ & $290 \mathrm{~K}$ & $323 \mathrm{~K}$ & $333 \mathrm{~K}$ \\
\cline { 2 - 5 } & $0.87 / 0.68^{*}$ & $0.91 / 0.72$ & $0.93 / 0.74$ & $0.99 / 0.77$ \\
\hline 0 & $0.76 / 0.69$ & $0.73 / 0.66$ & $0.75 / 0.63$ & $0.82 / 0.65$ \\
\hline 2 & $0.81 / 0.71$ & $0.84 / 0.73$ & $0.82 / 0.76$ & $0.89 / 0.78$ \\
\hline 7 & &
\end{tabular}

Note: * values for the heat-treated samples

Water diffusion coefficient in PLA-based materials at different temperatures

\begin{tabular}{|c|c|c|c|c|c|c|}
\hline \multirow{2}{*}{$\begin{array}{c}\text { Water temperature, } \\
\mathrm{K}\end{array}$} & \multicolumn{6}{|c|}{ Diffusion coefficient $D \cdot 10^{12}, \mathrm{~m}^{2} / \mathrm{s}$} \\
\cline { 2 - 7 } & Pure PLA & $+2 \%$ of talc & $+7 \%$ of talc & $\begin{array}{c}\text { Heat-treated } \\
\text { pure PLA }\end{array}$ & $\begin{array}{c}+2 \% \text { of talc, } \\
\text { heat-treated }\end{array}$ & $\begin{array}{c}+7 \% \text { of talc, } \\
\text { heat-treated }\end{array}$ \\
\hline 276 & 2.45 & 1.18 & 2.43 & 1.91 & 0.81 & 1.34 \\
\hline 290 & 2.99 & 1.51 & 3.02 & 2.31 & 1.12 & 1.72 \\
\hline 323 & 3.18 & 2.09 & 3.27 & 2.59 & 1.32 & 2.01 \\
\hline 333 & 3.36 & 2.14 & 3.42 & 2.85 & 1.46 & 2.07 \\
\hline
\end{tabular}


It is known that the mass transfer of water in nonporous (in kinetic and sorption regard) polymer materials is varied in two features [18]: (i) diffusion of molecules in the material consisting of amorphous and crystalline phases with different diffusion properties is carried out mainly through the amorphous part of the polymer, while the diffusion conductivity of the crystallites can be neglected; (ii) the migration of water molecules proceeds by its diffusion not through the rigidly fixed pores, but through "cavities" in the polymer matrix. Mentioned "cavities" disorderly appear and disappear due to the thermal movement of macromolecule segments according to the probability laws. These assumptions are confirmed by the obtained data concerning the diffusion coefficients for the developed polylactide materials. In particular, there is a significant decrease in the diffusion coefficient of PLA after heat treatment; this is mostly due to the increase in the crystallinity degree of polylactide, as well as the compaction of the structure. The diffusion coefficient decrease is also observed for talc-filled materials; obviously, talc prevents the movement of water molecules in the material due to its hydrophobic properties, as well as leads to a compaction of the PLA structure of the composite. In this case, the greatest talc impact is appropriate for the heat-treated materials with $2 \mathrm{wt} \%$ of the talc. Most likely, with some increase in the filler content in the material structure, a significant number of transition layers of filler-talc is formed which possess a relatively high permeability in the relation to the water molecules.

The polymer polarity significantly affects the process of water diffusion into the polymer. The greater polymer polarity, the stronger internally molecular and intermolecular interactions, and more difficult to overcome them with polar water molecules [19]. Therefore, the polar polymers, in particular PLA, are characterized by high barrier properties in relation to the water.

It was found that the diffusion coefficient, regardless of the filler content and additional heat treatment increases with the increasing of water temperature. The temperature dependence of the diffusion coefficient in polymer materials is well approximated by the Arrhenius equation (4).

Based on the data obtained, the activation energy of the process of diffusion water-absorption by PLA has been calculated. Fig. 3 presents the value of activation energy of the water absorption process of PLA-based composites depending on the filler content and heat treatment.

It is determined that the adding of talc causes an increase in the activation energy of the water absorption process, at the same time, additional heat treatment also increases the $E_{a}$ value of the process. Such regularities are connected, first of all, with the compaction of the PLA structure under the action of both the inorganic nucleator- filler and the crystallization process that takes place during the heat treatment. The $E_{a}$ values increase indicates the need for an additional energy to water molecules for the diffusion into the matrix due to the barrier effect of talc particles and PLA crystallites.

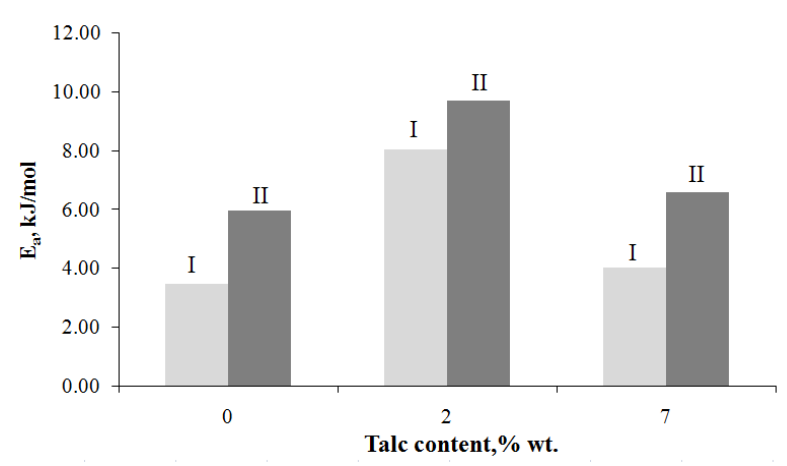

Fig. 3. The influence of filler content and heat treatment (I - without heat treatment, II - with heat treatment) on activation energy of water diffusion processes in the PLA

During their operation, the polymer composite materials are exposed not only to water, but also to aqueous solutions of acids or alkalis which are chemically active media consisting of various types of kinetic units: water and electrolyte molecules, hydrated molecules and ions, etc. Such multicomponent medium transfer through a polymer material has a complicated physico-chemical nature and depends on the nature, concentration and temperature of the medium, as well as the composition of the composite. In this case, the $\mathrm{pH}$ value of the medium significantly affects the proceeding of hydrolytic degradation of polylactide.

Thereby, the aggressive medium interaction with the polymer matrix and the filler should be taken into account when developing the polymer composite materials [20]. It is also advisable to study the effect of filler on chemical resistance of the obtained composites.

First of all, it should be noted that polylactide can be destroyed by the hydrolysis mechanism: water breaks the ester bonds. In this case two modes of degradation could be presented: 1) If the hydrolysis rate is higher than the diffusion rate, the surface or heterogeneous degradation occurs and only the polymer surface undergoes degradation and erosion (namely the weight loss), and the bulk remains undamaged. The shape of the sample remains the same, but its volume decreases over time; 2) If the water penetration occurs much faster than the water consumption, the uniform or volumetric degradation takes place: the rate of degradation is almost the same at each point of the matrix and the volume is not changed significantly over time. Weight losses are observed after a certain period of time, when the stratification of the chains has led to the oligomeric 
products formation. Mentioned products are mobile enough to diffuse through the matrix into the environment. During hydrolysis, there is an initial increase in the crystallinity degree which can be explained by two main reasons: better degradation of the amorphous phase and the forming of new crystalline formations transformed from amorphous chains. The described phenomenon is probably accelerated by neighboring water molecules, oligomers or monomers which can facilitate the chain mobility.

The results of fine-dispersed filler and heat treatment influence on the polylactide composites resistance to the action of $5 \% \mathrm{H}_{2} \mathrm{SO}_{4}$ solution are shown in Fig. 4.

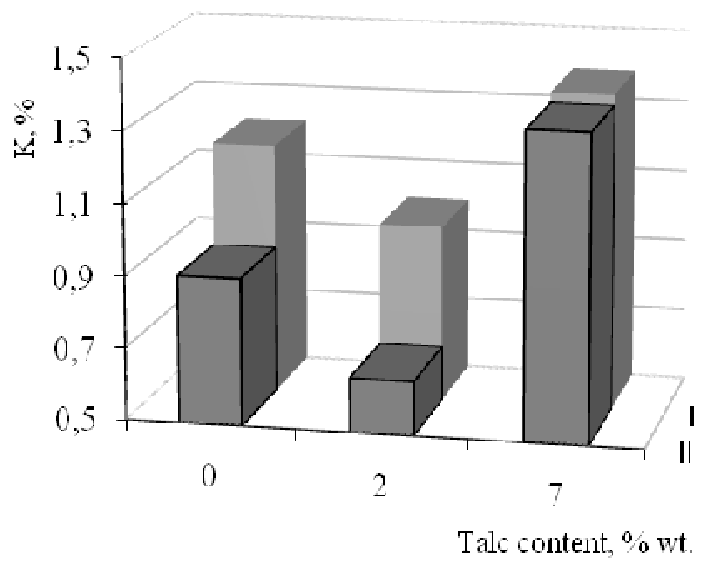

Fig. 4. Influence of talc content and heat treatment (I - without heat treatment; II - with heat treatment) on the swelling coefficient of PLA composites in $5 \% \mathrm{H}_{2} \mathrm{SO}_{4}$ solution

The $\mathrm{pH}$ value has a significant impact on the hydrolytic degradation of PLA because it affects both the reaction mechanism and the kinetics of the reaction.

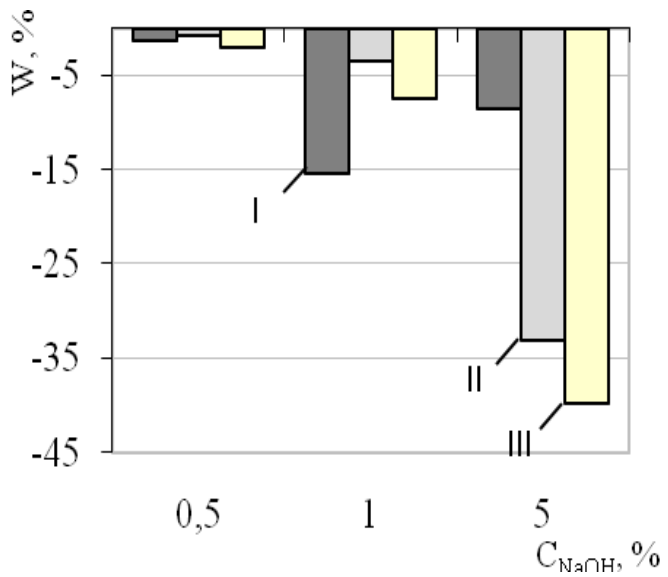

Fig. 5. Chemical resistance of PLA composites $\left(10^{\text {th }}\right.$ day). Filler content (wt \%): 0 (I); 2 (II) and 7 (III)
Certainly, the polylactide degradation reactions can occur via hydrolytic degradation of ester groups in various ways: acid catalyzation, basic catalyzation and catalyzation free. The research has shown that the end ester groups break down faster than the ester groups of the main chain.

It should be noted that the composites after 12 days of exposure in a $5 \%$ solution of $\mathrm{H}_{2} \mathrm{SO}_{4}$ are characterized by the high mixed diffusion behavior and the swelling coefficient $(K)$ of the samples is $0.7-1.6 \%$. Talc addition, as well as an additional heat treatment of PLA composites leads to an increase in chemical resistance of an acidic medium. It was found that the mechanism of hydrolysis at acidic $\mathrm{pH}$ occurs through the chain splitting.

In this case, the splitting of end ester groups promotes the faster weight loss of the polymer as a result of obtaining soluble low molecular weight polylactide oligomers. The reaction does not depend on the chain length and proceeds through the final $-\mathrm{OH}$ group.

The influence of alkaline medium on the chemical resistance of the developed polylactide materials was defined (Figs. 5 and 6).

Based on the research results it was found that independently of filler amount and the heat treatment during the exposure of composites in an alkaline medium all samples are characterized by a significant weight loss. Described loss relates to the leaching of the filler and water-soluble products, mainly lactic acid and probably low molecular weight oligomers from the composite during PLA degradation in the water. Visual observations also showed that polylactide composites which were immersed in alkali solutions, irrespective of their concentration, have lost transparency and became brittle. Thus, it was found that the $\mathrm{pH}$ value significantly influences the degradation velocity of polylactide.

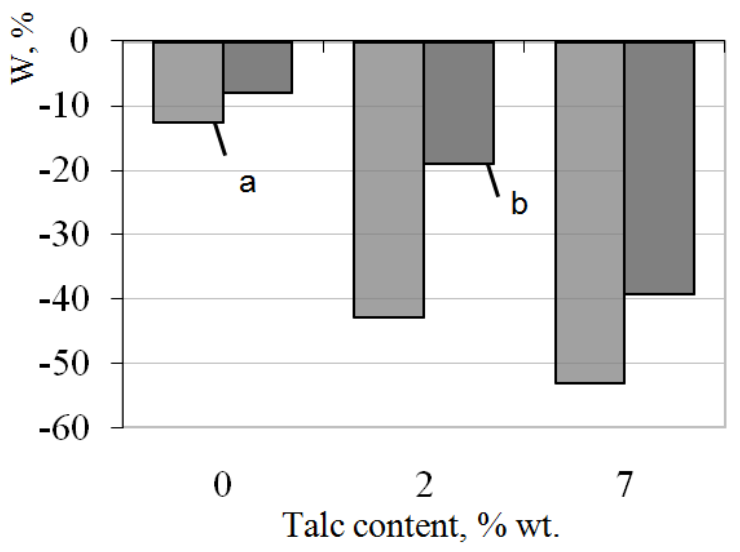

Fig. 6. Chemical resistance of PLA composites to the action of $5 \% \mathrm{NaOH}$ depending on heat treatment $\left(14^{\text {th }}\right.$ day): without heat treatment (a); with heat treatment (b) 


\section{Conclusions}

Based on the research results obtained it the influence of filler-talc amount, its content, as well as the heat treatment and temperature of the water medium on the regularities of water absorption of polylactide materials were revealed. It was established that the equilibrium water absorption of PLA materials is insignificant and makes $0.6-1 \mathrm{wt} \%$. As the result the process of water absorption occurs in two stages. In this case, the adding of talc in the amount of $2-7 \mathrm{wt} \%$ in PLA, and an additional heat treatment promote the reduction of polylactide equilibrium water absorption.

It was found that with the increasing temperature the diffusion coefficient of water through the polymer being raised. The addition of talc and a heat treatment of composites lead to the decrease in the diffusion coefficient and the increase in the activation energy of the water absorption process. In this case, the highest values of activation energy and the lowest diffusion coefficient are typical for the heat-treated materials with $2 \mathrm{wt} \%$ of the talc.

It was found that PLA composites after 12 days of exposure in a $5 \%$ solution of $\mathrm{H}_{2} \mathrm{SO}_{4}$ are characterized by a two-stage diffusion behavior and the swelling coefficient of the samples is $0.7-1.6 \mathrm{wt} \%$. The adding of talc and additional heat treatment of samples promote the increase of chemical resistance in an acidic medium which is probably due to the following changes in the morphology of polylactide: an increase in the degree of its crystallinity and the structure compaction. It was determined that regardless of the filler amount and heat treatment conditions, during the exposure of PLA composites in $0.5-5 \% \mathrm{NaOH}$ solution, for all the samples the significant weight loss of $35-70 \mathrm{wt} \%$ is typical. It is obviously due to leaching of filler and water-soluble products from the composite during the degradation of polylactide in an alkaline medium.

\section{References}

[1] Niaounakis M.: Biopolymers: Applications and Trends. William Andrew, Oxford 2015.

[2] Thakur V., Thakur M., Pappu A.: Hybrid Polymer Composite Materials. Woodhead Publishing Ltd, Cambridge 2017.

[3] Sin L-T.., Tueen B.-S.: Polylactic Acid, $2^{\text {nd }}$ edn. A Practical Guide for the Processing, Manufacturing, and Applications of PLA. William Andrew, Oxford 2019.

[4] Murariu M., Dubois P.: Advan. Drug Deliv. Rev., 2016, $107,17$. https://doi.org/10.1016/j.addr.2016.04.003

[5] Jiménez A., Peltzer M., Ruseckaite R.: Poly(lactic acid) Science and Technology: Processing, Properties, Additives and
Applications. Royal Society of Chemistry, Cambridge 2014. https://doi.org/10.1039/9781782624806

[6] Carrasco F., Pages P., Gamez-Perez J. et al.: Polym. Degrad. Stab., 2010, 95, 116.

https://doi.org/10.1016/j.polymdegradstab.2009.11.045

[7] Tokiwa Y, Calabia B.: Appl. Microbiol. Biotechnol., 2006, 72, 244. https://doi.org/10.1007/s00253-006-0488-1

[8] Stloukal P., Kalendova A., Mattausch H. et al.: Polym. Test., 2015, 41, 124. https://doi.org/10.1016/j.polymertesting.2014.10.015 [9] Xu L., Crawford K., Gorman C.: Macromolecules, 2011, 44, 4777. https://doi.org/10.1021/ma2000948

[10] Levytskyi V., Masyuk A., Bilyi L. et al.: Mater. Sci., 2020, 55, 555. https://doi.org/10.1007/s11003-020-00338-9

[11] Di Lorentso M., Androsch R.: Industrial Applications of Poly(lactic acid). Springer, New York 2018.

https://doi.org/10.1007/978-3-319-75459-8

[12] Moravskyi V., Levytskyi V., Bratychak Jr. M. et al.: Chem. Chem. Technol., 2019, 14, 347.

https://doi.org/10.23939/chcht13.03.347

[13] Saha S. Tsuji H.: Polym. Degrad. Stab., 2006, 91, 1665.

https://doi.org/10.1016/j.polymdegradstab.2005.12.009

[14] Androsch R., Schick C., Di Lorenzo M.: Adv. Polym. Sci., 2016, 279, 235. https://doi.org/10.1007/12_2016_13

[15] Levytskyj V., Laruk Yu., Humenetsky T., Sikora J.: Chem. Chem. Technol., 2015, 9, 199.

https://doi.org/10.23939/chcht09.02.199

[16] Koenig J.: Spectroscopy of Polymers, $2^{\text {nd }}$ edn. Elsevier Science.

New York 1999. https://doi.org/10.1016/B978-044410031-3/50005-0

[17] Levytskyj V., Kochubei V., Gancho A.: Chem. Chem.

Technol., 2013, 7, 169. https://doi.org/10.23939/chcht07.02.169

[18] Faghri A., Zhang Y.: Transport Phenomena in Multiphase

Systems. Academic Press, Cambridge 2006.

https://doi.org/10.1016/B978-0-12-370610-2.50007-6

[19] Suberlyak O., Levitskij V., Skorokhoda V., Godij A.: Ukr.

Khim. Zh., 1998, 5-6, 122.

[20] Katruk D., Levytskyi V., Khromyak U. et al.: Int. J. Polym.

Sci., 2019, 2019, 1. https://doi.org/10.1155/2019/2547384

Received: July 10, 2020 / Revised: July 27, 2020 / Accepted: September 13, 2020

\section{СТІЙКІСТЬ ПОЛІЛАКТИДНИХ МАТЕРІАЛІВ ДО ВОДНИХ СЕРЕДОВИЩ РІЗНОЇ ПРИРОДИ}

\begin{abstract}
Анотація. Досліджено вплив наповнювача (тальку), його кониентрації, додаткового термооброблення $i$ температури на закономірності водопоглинання полілактидних матеріалів. На основі отриманих даних визначено коефіцієнт дифузії води в полілактидних матеріалах та енергію активаиіі процесу дифузії. Виявлено, щчо процес водопоглинання наповненими і термообробленими матеріалами на основі полілактиду відбувається повільніше і потребує більшої енергії активаиії прочесу. Визначено стійкість розроблених полілактидних матеріалів до кислого і лужного середовищ, зокрема виявлено що в лужному середовищі руйнування полілактидних зразків відбувається швидие ніж в кислому.
\end{abstract}

Ключові слова: полілактид, водопоглинання, хімічна стійкість, тальк, теромооброблення. 